\title{
A Cost Analysis of Salbutamol Administration by Metered-Dose Inhalers with Spacers versus Nebulization for Patients with Wheeze in the Pediatric Emergency Department: Evidence from Observational Data in Nova Scotia
}

\author{
Paul Spin, MA, PhD ABD*; Ingrid Sketris, PharmD, MPA(HSA) ${ }^{\dagger}$; Barbara Hill-Taylor, BSP, MLIS $^{\dagger}$; \\ Courtney Ward, MA, PhD*; Katrina F. Hurley, MD, MHI
}

\section{ABSTRACT}

Background: Despite evidence demonstrating the advantages of metered-dose inhalers with spacers (MDI-s), nebulization (NEB) remains the primary method of asthma treatment in some pediatric emergency departments (PEDs). There is a perception that delivering salbutamol by MDI-s is more costly than by NEB. This research evaluates the relative costs of MDI-s and NEB using local, hospital-specific, patientlevel data.

Methods: Regression models estimated associations between the salbutamol inhalation method and costs, length of stay (LOS) in the PED and hospital, and the probability of admission. Our population was a random sample of 822 patients presenting with wheeze to the PED in 2008/2009. Control variables included age, sex, triage acuity, time of PED visit, other medications, and vitals. Costs were calculated using the prices and quantities of medical resources used per treatment. Probabilistic sensitivity analysis was used.

Results: Treatment with MDI-s versus NEB was associated with an absolute decrease in hospitalization of $4.4 \%(p<0.05)$ and a 25 -hour $(p<0.001)$ reduction in average inpatient stay, after controlling for triage acuity and patient characteristics. This resulted in savings of $\$ 24 /$ patient in the PED and $\$ 180$ / patient overall $(p<0.001)$. Inpatient care accounted for more than $90 \%$ of total patient costs.

Conclusions: Our results suggest economic gains associated with MDI-s for salbutamol inhalation in PEDs. Sensitivity analyses show that this conclusion is not affected by changes in model parameters that may differ by jurisdiction. Since most facilities already collect the data used for this study, our methods could be adopted for a cross-jurisdictional account of the cost effectiveness of MDI-s.

\section{RÉSUMÉ}

Contexte: Malgré l'existence de données qui démontrent les avantages de l'aérosol-doseur avec tube d'espacement (ADTE), le nébuliseur (NEB) reste le principal moyen de traitement de l'asthme dans certains services des urgences pédiatriques (SUP). L'administration de salbutamol par ADTE, croit-on, coûte plus cher que celle par NEB. La recherche décrite ici visait donc à évaluer le coût de l'utilisation de I'ADTE par rapport à celui de l'utilisation du NEB à l'aide de données locales, propres à un hôpital et relatives aux patients.

Méthode: Des modèles de régression ont permis d'estimer des associations entre les moyens d'administration de salbutamol et les coûts, le séjour au SUP et à l'hôpital ainsi que les probabilités d'hospitalisation. La population à l'étude se composait d'un échantillon aléatoire de 822 patients qui présentaient une respiration sifflante au SUP, en 2008 et en 2009. Les variables de contrôle comprenaient l'âge, le sexe, le degré de gravité au moment du triage, I'heure de consultation au SUP, I'emploi d'autres médicaments et les signes vitaux. Le calcul des coûts tenait compte des prix et de la quantité de ressources médicales employées par traitement. Enfin, les auteurs ont procédé à une analyse de sensibilité probabiliste. Résultats: Le traitement par ADTE comparativement à celui par NEB a été associé à une diminution absolue de $4,4 \%$ $(p<0,05)$ du nombre d'hospitalisations et à une réduction de 25 heures $(p<0,001)$ du séjour moyen à I'hôpital, et ce, après la neutralisation du degré de gravité au moment du triage et des caractéristiques des patients. Dans les faits, ces chiffres se traduisent par une économie de 24 \$/patient au SUP et, dans I'ensemble, de $180 \$ /$ patient $(p<0,001)$. Les soins aux hospitalisés représentaient plus de $90 \%$ des coûts totaux liés au traitement des patients.

From the *Department of Economics; †IMPART, College of Pharmacy, Faculty of Health Professions; and $¥$ Department of Emergency Medicine, Dalhousie University, Halifax, NS.

Correspondence to: Katrina Hurley, Department of Emergency Medicine, Dalhousie University and the IWK Health Centre, Emergency Department, 5850/5980 University Avenue, PO Box 9700, Halifax, NS, B3K 6R8; Email: kfhurley@dal.ca 
Conclusions: Les résultats de l'étude portent à croire qu'il existe des économies associées à l'administration de salbutamol par ADTE, dans les SUP. Les analyses de sensibilité ont démontré que les modifications des paramètres des modèles, susceptibles de varier selon les gouvernements étaient sans incidence sur la conclusion. Comme la plupart des établissements font déjà la collecte de données utilisées dans l'étude en question, il serait possible d'adopter les méthodes décrites ici pour procéder à une mesure pangouvernementale du rapport coût-efficacité de I'utilisation de I'ADTE.

Keywords: Economic models, health care quality, health care access, health care evaluation, salbutamol, paediatric hospital

\section{INTRODUCTION}

Wheeze leads to frequent presentations to pediatric emergency departments (PEDs). ${ }^{1}$ Salbutamol, a betaagonist often used to treat wheeze, was traditionally administered by nebulization (NEB). However, evidence shows that salbutamol administered by metered-dose inhalers with valved spacers (MDI-s) offers advantages to pediatric patients. ${ }^{2}$ Salbutamol administered by MDI-s is associated with less tachycardia and tremor, decreased PED length of stay (LOS), and decreased risk of admission. $^{2}$ MDI-s also result in increased child and parent treatment satisfaction and may reduce staff and caregiver risk during respiratory infection epidemics. ${ }^{3-5}$ Although PEDs in Canada are now accepting MDI-s as the route of choice for salbutamol inhalation, ${ }^{6}$ one of the factors linked to resistance to switching salbutamol inhalation methods is the perception of increased costs. ${ }^{7,8}$

The cost-effectiveness of MDI-s versus NEB has been documented, ${ }^{4,9-12}$ but no published Canadian study has used local clinical and administrative data in their analysis. One Canadian study estimated cost-savings of \$155 per PED visit associated with salbutamol delivery via MDI-s. ${ }^{10}$ Doan and colleagues used hospital-level data for medication, labour and equipment costs, but drew on a systematic review of randomized controlled trials for patient outcomes. ${ }^{2}$ While cross-regional extrapolation of epidemiological outcomes is commonly accepted in health economic evaluations, clinical outcomes such as LOS and hospitalization rates may be less generalizable because of jurisdictional variations in socioeconomic status, practice variability, and supply of health care resources. ${ }^{13-15}$ Our objective was to conduct an economic evaluation of both salbutamol inhalation methods based on local, hospitalspecific patient-level outcome and cost data.

\section{METHODS}

Approval was obtained from the Research Ethics Board of the IWK Health Centre (\#1012427, September 28, 2012). Consolidated Health Economic Evaluation
Reporting Standards (CHEERS) were used in the development of this paper. ${ }^{16}$

\section{Data collection}

The setting was the IWK Health Centre, the tertiary care pediatric facility for Maritime Canada. The IWK PED sees approximately 28,000 children per annum, with approximately 2,000 (7.1\%) presenting with an acute wheeze-related illness. Our cohort was established in a previous study. ${ }^{17}$ A random sample of 1,376 children were chosen from the 4,140 patients diagnosed with asthma (J45), bronchiolitis (J21), other respiratory disorders (J98.8), or wheeze (R06.2) (International Statistical Classification of Disease and Related Health Problems, 10th Revision, Canada) between January 1, 2008December 31, 2009. Multiple sources were used to obtain retrospective data and model parameters (see Table 1).

Data from the patient chart review were linked with data from the Discharge Abstract Database and National Ambulatory Care Reporting System to provide a patient-level data set. Each record represents a visit to the PED and captures age, sex, visit date and time, triage acuity, vitals, salbutamol inhalation method, total dosage, other medications given (ipratropium bromide and dexamethasone), PED and hospital LOS, and disposition. (Table 1)

We excluded patients whose data did not match between chart review, DAD and NACRS $(n=191)$, patients who received both or neither methods of salbutamol inhalation $(n=245)$ and those with missing or invalid data values $(\mathrm{n}=118)$. Our final sample numbered 822 visits.

\section{Study perspective and discounting}

Our analysis takes the hospital's perspective. That is, our analysis did not include private or societal costs and benefits. Physician costs were not included, as PED physicians at the IWK are paid a rate per shift which is not dependent 


\begin{tabular}{|c|c|}
\hline Data Sources & Variables and Model Parameters \\
\hline The National Ambulatory Care Reporting System (NACRS)* & $\begin{array}{l}\text { Patient's age, sex, triage level, time and date (year and quarter) of PED visit, } \\
\text { patient disposition }\end{array}$ \\
\hline Patient chart review & $\begin{array}{l}\text { Respiratory rate, oxygen saturation, heart rate, other drugs administered, } \\
\text { PED length of stay }\end{array}$ \\
\hline Discharge Abstract Database (DAD) $\dagger$ & Inpatient length of stay \\
\hline Nova Scotia Nurses Union $\ddagger$ & Wages and salaries for registered nurses (RN-2 pay scale) \\
\hline Time and motion study by Mason et al. ${ }^{11}$ & Time used by nurses to perform MDI-s and NEB procedures \\
\hline Pharmacy inventory data, IWK Health Centre & Unit cost of salbutamol nebule, mask, tubing, spacer, and MDI \\
\hline $\begin{array}{l}\text { Canadian Institution of Health Information Patient Cost } \\
\text { Estimator for } 2010-2011 \S\end{array}$ & Inpatient costs for asthma patients aged 1-7 years in Nova Scotia \\
\hline Statistics Canada CANSIM Table 326-0020 & Consumer Price Index \\
\hline \multicolumn{2}{|c|}{$\begin{array}{l}\text { PED = Pediatric Emergency Department; MDI = metered-dose inhaler; MDI-s = metered-dose inhaler with valved spacer; NEB = wet nebulization. } \\
\text { *http://www.cihi.ca/CIIII-ext-portal/internet/en/document/types+of+care/hospital+care/emergency+care/NACRS_METADATA. } \\
\text { thttp://www.cihi.ca/CIHI-ext-portal/internet/en/document/types+of+care/hospital+care/acute+care/dad_metadata. } \\
\text { fhttps://www.nsnu.ca/en/home/default.aspx. } \\
\text { Shttp://www.cihi.ca/cihi-ext-portal/internet/en/applicationnew/types+of+care//hospital+care/cihio20209. } \\
\text { १http://www5.statcan.gc.ca/cansim//a26?lang=eng\&id=3260020. }\end{array}$} \\
\hline
\end{tabular}

on patient volume or treatment choices. We did not perform present-value discounting, as all costs and clinically relevant outcomes occurred shortly after treatment.

\section{Calculating cost of treatment}

Patient-level costs were calculated using our hospital data on treatment method, dosage, and disposition, with local information on the cost of supplies, nursing time ${ }^{11}$ and inpatient care. Table 2 describes the supplies and time required for each round of treatment, including the monetary cost per treatment. We used the patient's recorded dosage of salbutamol and the IWK Health Centre's Asthma Care Map (available on request) to derive the total number of treatments received by a patient while in the PED.

All costs and prices were converted to 2010 constant Canadian dollars prior to calculating costs of treatment. Cost estimates were also converted into U.S. dollars. We also compared our cost estimates to others found in the literature. Where appropriate, citations of treatment costs from international jurisdictions were converted into Canadian dollars using foreign/Canadian exchange rates for the year of publication (http://fxtop. com), and then adjusted to 2010 constant dollars.

\section{Analytic methods}

We describe our data set using sample counts by selected patient groups. Means (95\% confidence intervals) were calculated for the both patient groups. Regression models were used to estimate differences in outcomes and costs between groups. Because admissions and LOS in both the PED and hospital are significant drivers of treatment costs, all three clinical measures were used as dependent variables. Control variables included age, sex, triage acuity, patient vitals (e.g., respiratory rate, oxygen saturation, heart rate), date of PED visit, and the use of other medications. Baseline heart, respiratory rates, and oxygen saturation were converted to age-based Canadian Triage and Acuity Scale (CTAS) categorical scales prior to their inclusion in the regression models. ${ }^{18}$

Logistic regressions were used to estimate admission probabilities, while Poisson regressions were used for PED and inpatient LOS. Generalized linear models (GLMs) specified with a log-link and Gamma distribution were used to model inpatient and PED costs. Since $85 \%$ of visits to the PED resulted in a discharge and, therefore, zero inpatient costs, we adopted a two-part model for evaluating inpatient costs. In this case, we separately modeled the probability of inpatient admission and the level of inpatient costs among hospitalized patients. The estimates generated from these two models were combined to derive a single estimate of the difference in inpatient cost between the two treatment groups.

All analyses were conducted using Stata12.1 (www. stata.com).

\section{Sensitivity analysis}

We performed two sensitivity analyses to explore the sensitivity of our results to changes in the parameter 


\begin{tabular}{|c|c|c|c|}
\hline & Resource Use & $C D N \$ * /$ Unit & CDN\$/Patient, 1 treatment \\
\hline \multicolumn{4}{|l|}{ MDI-s } \\
\hline MDIt & 1 unit /patient & 2.95/Unit & $2.95 \ddagger$ \\
\hline Spacer§ & 1 unit/5 patients & 33.07/Unit & 6.61 \\
\hline \multirow[t]{2}{*}{ Nursing Time } & 140.4 seconds/treatment & 31.88/hour & 1.24 \\
\hline & & & Total $=10.80$ \\
\hline \multicolumn{4}{|l|}{$N E B$} \\
\hline Mask & 1 unit/patient & 0.97/Unit & 0.97 \\
\hline Tubing & 1 unit/patient & 0.27/Unit & 0.27 \\
\hline Nebule & $1 /$ treatment & 0.43/Unit & 0.43 \\
\hline Nursing Time & 1,256.6 seconds/treatment & $31.88 /$ hour & 11.13 \\
\hline \multirow{2}{*}{ Salbutamolll } & $5 \mathrm{mg} /$ treatment & $0.06 / \mathrm{mg}$ & 0.30 \\
\hline & & & Total $=13.10$ \\
\hline \multicolumn{4}{|l|}{ MDI-s and NEB } \\
\hline Inpatient Cost & - & $1,077 /$ day & - \\
\hline \multicolumn{4}{|c|}{ 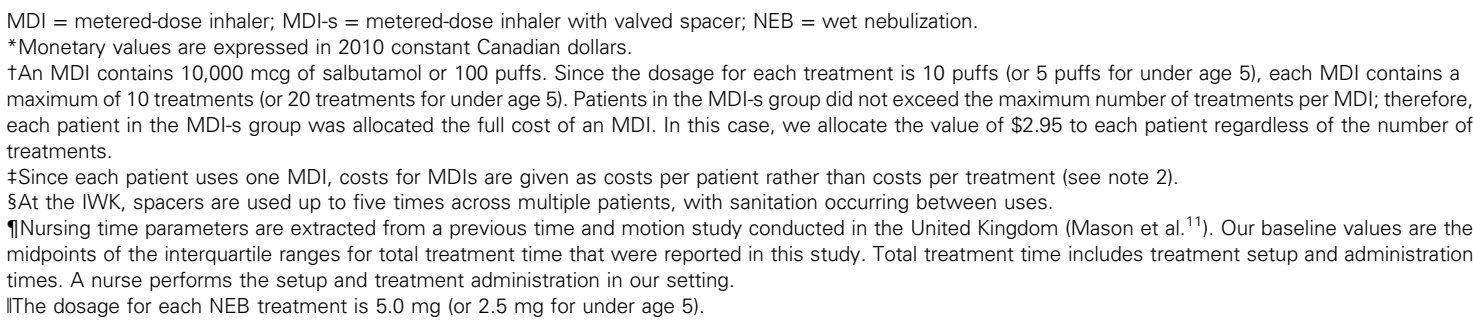 } \\
\hline
\end{tabular}

values used to calculate the costs. First we used a scenario in which we assumed that baseline parameter values were biased in favour of MDI-s. Under an alternative scenario, we replaced baseline MDI-s parameters with higher prices and more intensive resource use values, whereas baseline NEB parameters were replaced with lower prices. The second sensitivity analysis used a multi-way (probabilistic) sensitivity approach. In this case, parameter values were selected at random from probability distributions and then used to re-calculate patient costs. Once these costs were produced, we re-estimated our regression models. This procedure was replicated 10,000 times to derive a simulated distribution of cost differences between groups.

\section{RESULTS}

\section{Clinical and demographic characteristics}

Of the 822 patients analyzed, 664 were in the MDI-s group and 158 in the NEB group. Patients in the NEB group were 1.1 years younger and presented to the PED with more severe clinical symptoms as measured by triage acuity (Table 3).
Table 3. Selected Clinical and Demographic Patient Grouping

$\begin{array}{lccc}\text { Patient Group } & \text { MDI-s (n) } & \text { NEB (n) } & \begin{array}{c}\text { Treated with } \\ \text { MDI-s (\%) }\end{array} \\ \text { All patients } & 664 & 158 & 81 \\ \text { Female patients } & 230 & 62 & 79 \\ \text { Male patients } & 434 & 96 & 82 \\ \text { Age } \leq 2 \text { years } & 295 & 97 & 75 \\ \text { Age >2 years } & 369 & 61 & 86 \\ \text { Triage I-II* } & 218 & 88 & 71 \\ \text { Triage III-IV* } & 446 & 70 & 86 \\ \text { Hospitalized } & 74 & 54 & 58 \\ \text { Discharged from PED } & 590 & 104 & 85 \\ \text { Use of dexamethasone } & 513 & 89 & 85 \\ \text { Use of ipratropium } & 65 & 31 & 68 \\ \text { MDI-s = metered-dose inhaler with spacer; NEB = wet nebulization; PED = Pediatric } \\ \text { Emergency Department. } \\ \text { *Triage = Canadian Triage and Acuity Scale (CTAS). }\end{array}$

\section{Patient outcomes and costs}

Our summary statistics (Table 4) show that MDI-s treatment is associated with lower costs and improved clinical outcomes. For example, only $11 \%$ of those in the MDI-s group were admitted after treatment in the PED, compared to one-third of those in the NEB group. Costs in the 
Cost Analysis of Salbutamol by Metered-Dose Inhalers vs Nebulization in the Pediatric ED

\begin{tabular}{|c|c|c|c|}
\hline Variables & MDI-s $(95 \% \mathrm{Cl})$ & NEB $(95 \% \mathrm{Cl})$ & $p$ Value of Difference \\
\hline \% Admission to Inpatient Care & $\begin{array}{c}11 \\
(9,14)\end{array}$ & $\begin{array}{c}34 \\
(27,42)\end{array}$ & $<0.001$ \\
\hline $\begin{array}{l}\text { LOS in ED } \\
\text { (hrs) }\end{array}$ & $\begin{array}{c}3.05 \\
(2.95,3.15)\end{array}$ & $\begin{array}{c}2.62 \\
(2.43,2.81)\end{array}$ & $<0.001$ \\
\hline $\begin{array}{l}\text { LOS inpatient } \\
\text { (hrs) }\end{array}$ & $\begin{array}{c}31.98 \\
(26.01,37.94)\end{array}$ & $\begin{array}{c}62.62 \\
(41.19,84.04)\end{array}$ & 0.0024 \\
\hline $\begin{array}{l}\text { Total Cost } \\
\text { (CDN\$) }\end{array}$ & $\begin{array}{c}173.18 \\
(127.83,218.53)\end{array}$ & $\begin{array}{c}997.87 \\
(613.19,1382.55)\end{array}$ & 0.0021 \\
\hline $\begin{array}{l}\text { Inpatient Cost } \\
\text { (CDN\$) }\end{array}$ & $\begin{array}{c}159.92 \\
(114.65,205.20)\end{array}$ & $\begin{array}{c}960.33 \\
(574.99,1345.67)\end{array}$ & $<0.001$ \\
\hline $\begin{array}{l}\text { ED Cost } \\
\text { (CDN\$) }\end{array}$ & $\begin{array}{c}13.26 \\
(13.06,13.45)\end{array}$ & $\begin{array}{c}37.54 \\
(33.09,41.99)\end{array}$ & $<0.001$ \\
\hline $\begin{array}{l}\text { Time Cost } \\
\text { (CDN\$) }\end{array}$ & $\begin{array}{c}3.69 \\
(3.50,3.89)\end{array}$ & $\begin{array}{c}31.43 \\
(27.75,35.11)\end{array}$ & $<0.001$ \\
\hline $\begin{array}{l}\text { Drug Cost* } \\
\text { (CDN\$) }\end{array}$ & 2.95 & $\begin{array}{c}0.52 \\
(0.45,0.59)\end{array}$ & $<0.001$ \\
\hline $\begin{array}{l}\text { Equipment Cost† } \\
\text { (CDN\$) }\end{array}$ & 6.61 & $\begin{array}{c}4.69 \\
(4.14,5.24)\end{array}$ & $<0.001$ \\
\hline \multicolumn{4}{|c|}{$\begin{array}{l}\text { LOS = length of stay; MDI = metered-dose inhaler; MDI-s = metered-dose inhaler with valved spacer; NEB = wet nebulization. } \\
\text { *Since the dosage for each treatment is } 10 \text { puffs (or } 5 \text { puffs for under age } 5 \text { ), each } \mathrm{MDI} \text { contains a maximum of } 10 \text { treatments (or } 20 \text { treatments for under age } 5) \text {. } \\
\text { Patients in the MDI-s group did not exceed the maximum number of treatments per puffer; therefore each patient in the MDI--s group was allocated the full cost of } \\
\text { an MDI. In this case, we allocate the value of } \$ 3.14 \text { to each patient regardless of the number of treatments. Consequently, the cost of drugs does not vary across } \\
\text { patients in the MDI-s group. } \\
\text { FFor the MDI-s group, the only equipment cost is the cost of the spacer. Spacers are used for up to five patients. We therefore assigned one-fifth of the cost of a } \\
\text { spacer to each patient in the MDI-s group. Like MDI-s, the cost of the spacer does not vary across patients in the MDI-s group. }\end{array}$} \\
\hline
\end{tabular}

NEB group were $\$ 998$ per patient-visit, compared to $\$ 173$ for MDI-s. Inpatient care accounted for more than $93 \%$ of total patient costs (96\% in NEB and $92 \%$ in MDI-s).

Tables 3 and 4 show summary statistics which do not control for confounding influences, including illness severity, additional medications and patient characteristics (e.g., CTAS, ipratropium, age). Table 5, however, shows regression-adjusted estimates that control for these baseline observed confounders. The addition of these controls reduces but does not eliminate group differences in patient costs and outcomes. For example, MDI-s is still associated with a $4.4 \%$ absolute reduction in probability of admission. Among admitted patients, those that received MDI-s in the PED spent 25 fewer hours in inpatient care compared to patients treated with NEB. Our results indicate that NEB and MDI-s patients had similar PED LOS.

MDI-s is also associated with lower treatment costs. Treatment via MDI-s is associated with a $\$ 180$ (US\$175) reduction in total costs per patient-visit. While almost 90\% (\$156 (US\$152)) of this reduction came in the form of lower inpatient costs, MDI-s was also associated with a \$24 (US\$23) reduction in PED costs.

Our scenario analysis (Table 5, Panel C) assumes greater resource intensity per treatment and higher equipment prices for MDI-s than at baseline. For example, under this scenario, it is assumed that spacers are used for three patients, rather than five as stated under our baseline assumptions. The analysis reduces the cost-savings of MDI-s from $\$ 180$ to $\$ 146$ (US $\$ 141)$. As before, cost-savings are driven by lower admission rates among patients treated with MDI-s. However, there is still PED cost-savings for MDI-s of \$5 (US\$4.85).

Figure 1 displays the results of the multi-way sensitivity analysis. Each point on the figure is an estimate of the cost-savings for MDI-s under a simulated set of input prices and resource use values for each treatment. Importantly, all of the simulated estimates indicate cost-savings for MDI-s. For example, the right tail of the distribution indicates that the use of MDI-s is associated with a minimum cost-savings of approximately $\$ 160$ (US\$155) per patient visit. 


\begin{tabular}{|c|c|c|c|}
\hline & Effect of MDl-s $(95 \% \mathrm{Cl})$ & PED $(95 \% \mathrm{Cl})$ & Hospital Admission (95\% Cl) \\
\hline \multirow[t]{3}{*}{ (A) Outcome } & Probability of Admission & Length of Stay (Hours) & Length of Stay (Hours) \\
\hline & $-0.044^{*}$ & 0.171 & $-24.95 * * *$ \\
\hline & $(-0.005,-0.083)$ & $(-0.201,0.543)$ & $(-23.52,-26.38)$ \\
\hline \multirow{3}{*}{$\begin{array}{l}\text { (B) Costs using baseline cost } \\
\text { parameters (see Table 2) }\end{array}$} & Total & & \\
\hline & $-180.35 * * *$ & $-23.55^{* * *}$ & $-156.80^{*}$ \\
\hline & $(-57.24,-303.46)$ & $(-19.69,-27.41)$ & $(-33.38,-280.22)$ \\
\hline \multirow{3}{*}{$\begin{array}{l}\text { (C) Costs assuming MDI-s is more } \\
\text { expensive than baseline }\end{array}$} & Total & & \\
\hline & $-146.5^{* *}$ & $-5.38 * * *$ & $-141.12^{*}$ \\
\hline & $(-35.66,257.34)$ & $(-2.79,-7.97)$ & $(-30.05,-252.19)$ \\
\hline
\end{tabular}

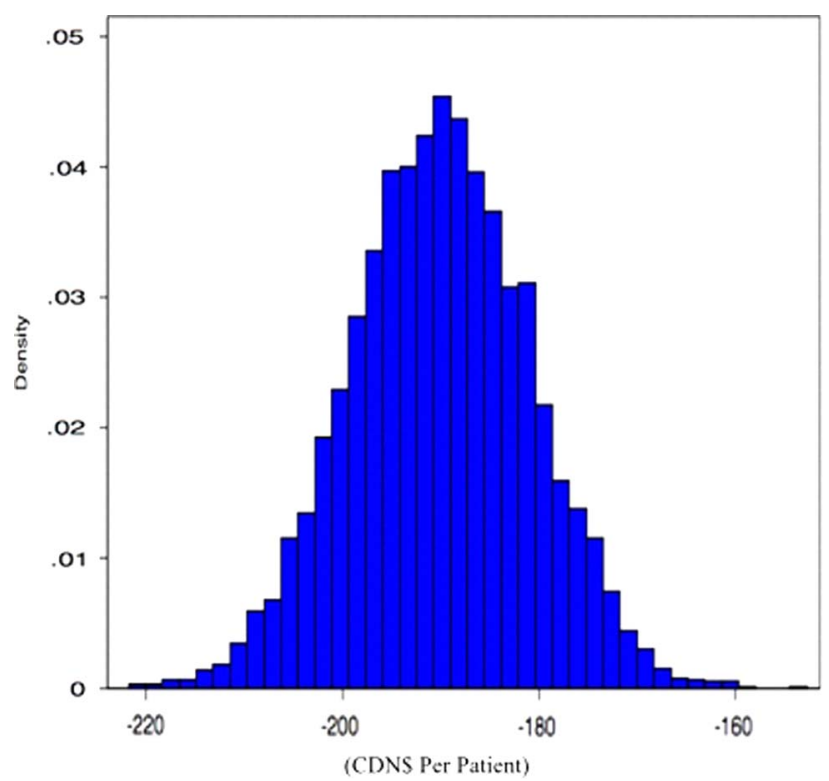

Figure 1. Simulated Distribution of Cost Savings Achieved by MDI-s.

Note: In the simulation, we allow prices and resource intensity values to range probabilistically according to different distributions. Here, distribution means are set according to the parameters given in Table 2 . The simulations are specified as follows: wages, nebulization equipment (e.g. masks, tubing, nebules), salbutamol and inpatient costs vary within $+/-10 \%$ of their means according to a normal distribution; nursing time for MDI-s varies from 92-188 seconds per treatment using a Gamma distribution; nursing time for nebulization varies from 806 seconds to 1725 seconds, also using a Gamma distribution; and spacers are used for 3-5 patients according to a uniform distribution.

\section{DISCUSSION}

Salbutamol inhalation by MDI-s is associated with lower admission rates and inpatient LOS, after controlling for observed differences between treatment groups in illness severity (e.g., CTAS, vitals, use of ipatropium) and patient characteristics (e.g., age, sex). This resulted in costsavings of $\$ 180(p<0.001)$ per patient, with most savings coming from lower admission rates. With approximately 2,000 patients presenting to our PED with an acute wheeze-related illness per year, even if only $75 \%$ are treated with salbutamol, the predominant use of MDI-s would realize total savings of $\$ 270,000$ (US\$262,000) per annum. Of these, $\$ 42,000$ (US\$41,000) per annum are direct savings to the PED.

While PED LOS was equivalent in both comparator groups, our model used the total treatment time as reported by the UK time and motion study, ${ }^{11}$ which was significantly higher for patients in the NEB group. The authors of the UK study measured administration and setup time separately and added the two to obtain total treatment time. At our PED, registered nurses perform setup and administration tasks, making total treatment time the most relevant model parameter. While PED cost differences are likely sensitive to setup time, PED costs make up only a small fraction of total patient costs at our institution.

Several studies have examined the economic impact of salbutamol inhalation procedures in emergency departments. ${ }^{9,11,12}$ In two studies, respiratory therapist or nursing costs for both procedures were assessed. ${ }^{9,11}$ Both studies found similar costs of drug, delivery system, and staffing for both inhalation methodssavings of US\$8.15 (CAN\$9.87) associated with MDI-s were reported in one study, ${ }^{9}$ while a loss of US\$7.33 (CAN\$8.87) for a single treatment was noted by another. ${ }^{11}$ However, the authors of the latter study 
noted that savings had switched in favour of MDI-s by the fourth or fifth treatment. Another study examined differences in treatment time, reporting a 25 -minute reduction in treatment time for MDI-s versus NEB. Based on historical ED charges, the authors estimate time-related cost-savings of US\$216 (CAN\$222) per patient-visit. ${ }^{12}$ The value of the assessment or education given in the PED when using MDI-s has yet to be assessed in comparative studies.

In addition, two studies examined cost-savings achieved through admission rate changes associated with MDI-s. ${ }^{4,10}$ Leversha and colleagues documented significantly decreased costs in patients aged one to four years in a New Zealand PED through reduced hospital admissions in patients using MDI-s. ${ }^{4}$ Their savings, NZ\$457 (CDN\$547) per patient, are more than twice ours. A Canadian study, using non-local clinical data, arrived at estimated savings with MDI-s versus NEB that is remarkably similar to ours (CDN\$155 versus $\$ 180) .{ }^{10}$

\section{STRENGTHS AND LIMITATIONS}

An important strength of our study is that it uses local patient-level clinical data, and local economic data from administrative sources. These data capture unique regional factors influencing treatment, admissions, and cost of treatment. Our results may not be generalizable to other health care systems because of work flow and practice culture. However, because we used data that are already collected in many jurisdictions, our methods can be used for cross-jurisdictional accounts of the costeffectiveness of MDI-s.

An important methodological limitation of our study is sample size, hindering our ability to assess differences in costs and outcomes by patient sub-group. The data are derived from paper-based medical records. To validate the accuracy of the abstraction process, a randomly selected $10 \%$ of the medical record reviews were repeated by an independent researcher. ${ }^{17}$ Kappa (к) for the inter-rater reliability test was 0.97 . Our data do not include patient co-morbidities or validated measures of asthma severity, and may be limited by other unmeasured confounding factors such as variations in physician choice of initial therapy in the PED and inpatient treatment.

We did not include administration costs involved in ordering drugs and supplies. Our time estimate for each visit is based on a UK time and motion study and may exclude the teaching time done in our PED to reinforce patient and caregiver MDI-s technique. Data limitations also precluded an assessment of patient relapse/ readmission. Our study did not deal with the advantages offered by, or technical and physical differences of, using MDI-s instead of NEB for the delivery of salbutamol. These differences have been addressed elsewhere. $^{19,20}$

\section{CONCLUSIONS}

We show that use of MDI-s for salbutamol inhalation in PEDs is associated with significant economic gains. Compared with NEB, MDI-s was associated with a 4.4\% absolute reduction in admission to hospital and reduced costs by $\$ 180$ per patient visit. These results suggest that broader adoption of MDI-s by other PEDs could result in substantial cost-savings.

Our study uses local data on patient outcomes, treatment protocols and input costs, thereby capturing unique regional factors influencing treatment, admissions, and costs. While these data are less transferable to other settings, we show, using sensitivity analyses, that our conclusions are not affected by changes in model parameters, such as treatment times or prices of medical supplies. Since most facilities collect the data used for this study, our methods could be adopted more widely for a cross-jurisdictional account of the cost effectiveness of MDI-s.

Acknowledgements: The authors would like to acknowledge the assistance of Dr. Kuan Xu (Dalhousie Economics) and Decision Support, IWK Health Centre.

Competing Interests: Funding was provided by a Category A Grant from the IWK Health Centre, and through Dr. I. Sketris' Chair in Health Service Research funded by the Canadian Health Services Research Foundation/Canadian Institute of Health Research, and co-sponsored by the Nova Scotia Health Research Foundation. The opinions, views and major findings from this project are those of the primary author and do not necessarily represent the views of the IWK PED. The authors have no conflicts of interest.

\section{REFERENCES}

1. Nelson KA, Zorc JJ. Asthma update. Pediatr Clin North Am 2013;60(5):1035-48, doi: 10.1016/j.pcl.2013.06.003.

2. Cates CC, Crilly JA, Rowe BH. Holding chambers (spacers) versus nebulisers for beta-agonist treatment of acute asthma. Cochrane Database Syst Rev 2006;2:CD000052. 
3. Cotterell EM, Gazarian M, Henry RL, et al. Child and parent satisfaction with the use of spacer devices in acute asthma. 7 Paediatr Child Health 2002;38(6):604-7.

4. Leversha AM, Campanella SG, Aickin RP, et al. Costs and effectiveness of spacer versus nebulizer in young children with moderate and severe acute asthma. $\mathcal{f}$ Pediatr 2000; 136(4):497-502.

5. Tran K, Cimon K, Severn M, et al. Aerosol Generating Procedures and Risk of Transmission of Acute Respiratory Infections to Healthcare Workers: A Systematic Review. PLoS One 2012;7(4):e35797, doi:10.1371/journal.pone.0035797.

6. Schuh S, Zemek R, Plint A, et al. Practice patterns in asthma discharge pharmacotherapy in pediatric emergency departments: a pediatric emergency research Canada study. Acad Emerg Med 2012;19(9):E1019-26, doi: 10.1111/j.1553-2712. 2012.01433.x.

7. Hurley KF, Sargeant J, Duffy J, et al. Perceptual reasons for resistance to change in the emergency department use of holding chambers for children with asthma. Ann Emerg Med 2008;51(1):70-7.

8. Scott SD, Osmond MH, O'Leary KA, et al. Barriers and supports to implementation of $\mathrm{MDI} /$ spacer use in nine Canadian pediatric emergency departments: A qualitative study. Implement Sci 2009; $4: 65$.

9. Dhuper S, Chandra A, Ahmed A, et al. Efficacy and cost comparisons of bronchodilatator administration between metered dose inhalers with disposable spacers and nebulizers for acute asthma treatment. 7 Emerg Med 2011;40(3):247-55, doi: 10.1016/j.jemermed.2008.06.029.

10. Doan Q, Shefrin A, Johnson D. Cost-effectiveness of metered-dose inhalers for asthma exacerbations in the pediatric emergency department. Pediatrics 2011;127(5):e1105-11.

11. Mason N, Roberts N, Yard N, et al. Nebulisers or spacers for the administration of bronchodilators to those with asthma attending emergency departments? Respir Med 2008;102(7):993-8.

12. Staggs L, Peek M, Southard G, et al. Evaluating the length of stay and value of time in a pediatric emergency department with two models by comparing two different albuterol delivery systems. $7 \mathrm{Med}$ Econ 2012;15(4):704-11, doi: 10.3111/13696998.2012. 674587.

13. Barbieri M, Drummond $M$, Rutten F, et al. What do international pharmacoeconomic guidelines say about economic data transferability? Value Health 2010;13(8): 1028-37.

14. Drummond M, Barbieri M, Cook J, et al. Transferability of economic evaluations across jurisdictions: ISPOR good research practices task force report. Value Health 2009; 12(4):409-18.

15. Canadian Agency for Drugs and Technologies in Health Guidelines for the economic evaluation of bealth technologies, 3rd ed.; 2006. Available at https://www.cadth.ca/media/pdf/ 186_EconomicGuidelines_e.pdf.

16. Husereau D, Drummond M, Petrou S, et al. Consolidated Health Economic Evaluation Reporting Standards (CHEERS) statement. Value Health 2013;16(2):e1-5, doi: 10.1016/j.jval.2013.02.010.

17. Wing A, Hill-Taylor B, Sketris I, et al. Medication records in the emergency department: agreement between paperbased charts and automated dispensing device. Can $\mathcal{F}$ Hosp Pharm 2012;65(4):265-71; Available at: http://cjhp-online. ca/cshp/index.php/cjhp/article/view/1156.

18. Warren DW, Jarvis A, LeBlanc L, et al. Revisions to the Canadian Triage and Acuity Scale Paediatric Guidelines (PaedCTAS). CFEM 2008;10(3):224-43.

19. Dolovich MB, Ahrens RC, Anderson P, et al. Device selection and outcomes of aerosol therapy: Evidence-based guidelines: American College of Chest Physicians/American College of Asthma, Allergy, and Immunology. Chest 2005;127(1):335-71, doi:10.1378/chest.127.1.335.

20. Hill-Taylor BJ, Hurley, Katrina F, Sketris I, et al. Evaluating a clinical practice intervention to promote delivery of salbutamol by metered-dose inhalers with holding chambers in a pediatric emergency department. CFEM 2013;15(2): $101-8$. 